Check for updates

Cite this: Mater. Adv., 2021, 2, 7741

Received 20th August 2021 Accepted 25th September 2021

DOI: 10.1039/d1ma00745a

rsc.li/materials-advances

\title{
Carbon-MEMS based rectangular channel microarrays embedded pencil trace for high rate and high-performance lithium-ion battery application $\uparrow$
}

\author{
Ananya Gangadharan, Suresh Kali, Suresh Mamidi, (D) * Anil D. Pathak and \\ Chandra S. Sharma (D)
}

\begin{abstract}
The miniaturization of a lithium-ion battery has been an aspiration in portable electronic devices and a possible method of implementation is by changing the electrode configuration from a $2 \mathrm{D}$ system to a 3D one. A carbon microelectromechanical system is a plausible execution of lithium-ion storage from 2D carbon films to 3D structures. However, the use of semiconducting silicon as a substrate for 3D structures and dendrite formation are hurdles. The present work describes the fabrication of 3D carbon rectangular channels on a pencil-traced stainless steel current collector and its utilization as the anode in a lithium-ion battery. Detailed physical and electrochemical studies demonstrate the advantage of this electrode in terms of reversible storage capacity and the establishment of a low resistance path for an electrochemical reaction. The cell exhibits an extraordinary capacity of $2000 \mathrm{~mA} \mathrm{~h} \mathrm{~g}{ }^{-1}$ at $150 \mathrm{~mA} \mathrm{~g}^{-1}$ and it retained a capacity of $\sim 400 \mathrm{~mA} \mathrm{~h} \mathrm{~g}^{-1}$ even at $10000 \mathrm{~mA} \mathrm{~g}^{-1}$ after 1750 cycles. Also, the full-cell prototype further proves the potency of this electrode. Additionally, the time-dependent Li-ion concentration gradient across the 3D carbon rectangular channels is estimated using a diffusion-limited model. These simulation studies clearly suggest that Li-ion diffusion is more favorable in 3D carbon rectangular channels than in $2 \mathrm{D}$ films.
\end{abstract}

\section{Introduction}

The miniaturization of portable electronic devices is demanded for high storage capacity compact batteries. ${ }^{1}$ In this regard, the replacement of the conventional planar geometry of the electrode with three-dimensional (3D) microarrays can be a remedial approach. ${ }^{2-4}$ The carbon microelectromechanical system (CMEMS) opens up a new avenue for various three-dimensional carbon geometries on a substrate. Marc Madou et al. introduced the concept of CMEMS and reported different 3D geometries on a silicon substrate. ${ }^{5,6}$ These carbon structures were explored in various electrochemical applications, such as batteries, supercapacitors, fuel cells, sensors, and solar cells. ${ }^{2,7-14}$ Wang et al. derived high aspect ratio carbon posts by the pyrolysis of a negative photoresist and verified the aptness of these carbon structures for a reversible lithium-ion intercalation/deintercalation process. $^{2}$

Creative \& Advanced Research Based On Nanomaterials (CARBON) Laboratory, Department of Chemical Engineering, Indian Institute of Technology Hyderabad, Kandi-502285, Sangareddy, Telangana, India.E-mail: ch14m16p000003@iith.ac.in $\dagger$ Electronic supplementary information (ESI) available. See DOI: 10.1039/ d1ma00745a
Further, F. Galobardes et al. investigated the formation of a solid electrolyte interface (SEI) on the CMEMS anode and the attribution to it of large irreversible capacity and charge transfer resistance. ${ }^{15}$ Hong Soek Min et al. extended CMEMS fabrication by creating positive electrode arrays of dodecylbenzene sulfonate doped polypyrrole (PPYDBS) on carbon posts using an electrochemical deposition technique. Their group successfully fabricated a prototype of a 3D C/PPYDBS full cell on a silicon substrate with a capacity of $10.6 \mu \mathrm{A} \mathrm{h} \mathrm{cm} \mathrm{cm}^{-2}$. However, its operation was limited due to an electrical short. ${ }^{4}$ Another turning point was the fabrication of cross-shaped CMEMS arrays, and the realization of their advantages over conventional carbon posts and the group proposed that crossshaped CMEMS with thinner features are favorable for the better utilization of carbon. ${ }^{14}$

The concept of 3D carbon structures has been explored in many ways rather than building only pyrolyzed SU-8 carbon posts on a silicon substrate. Different types of carbon structures are integrated with the SU-8 carbon posts and RF gel derived carbon posts. Sharma et al. reported RF gel derived 3D crossshaped and cylindrical shaped geometries and suspended SU-8 carbon nanofiber over carbon posts by a simple and efficient electrospinning method. ${ }^{16}$ Other reports show carbon nanowire 
integrated CMEMS; ${ }^{17}$ binder-free advanced matrix nanostructured electrodes $;{ }^{18}$ and the integration of SWNT/MWNT on carbon posts. ${ }^{19} \mathrm{~A}$ few reports show thin film deposition on the carbon posts by a sputtering method. ${ }^{20,21}$ However, the growth of the $3 \mathrm{D}$ carbon structures on a semiconducting silicon substrate is an issue for faster electron conduction in electrochemical storage devices. Therefore, our group optimized the parameters for the growth of high aspect ratio $3 \mathrm{D}$ carbon posts on a stainless steel (SS) substrate instead of a silicon substrate. ${ }^{11}$ From our previous study, we observed a dramatic increment in the capacity with cycle number without stabilization, resulting in a fall in the Coulombic efficiency of the battery. ${ }^{11}$ We scrutinized the electrochemical behavior of these batteries and summed up the possible reasons, which are: (i) lithium-ion reversibility in the high aspect ratio 3D carbon posts in vertical alignment is not efficient; (ii) there can be a direct contact of lithium ions with the substrate material, that can lead to malfunctioning of the battery; and (iii) inefficient utilization of the 3D carbon posts for reversible lithium-ion storage. To address these issues, in the present work, we fabricated an electrode with horizontally aligned high aspect ratio rectangular carbon channels on pencil-traced (graphitecoated) stainless-steel current collector (of a 2032 coin cell) for feasible lithium-ion storage. These rectangular channels can be more advantageous than a cylindrical carbon post geometry due to the direct interaction of lithium ions with the larger surface area of the electrode with the shortest diffusion path. Moreover, we found that the pencil-traced graphite layer avoids the direct contact of lithium ions with the stainless steel (SS) substrate through the embedded space between each channel. In this way, this thin layer of pencil-traced graphite simultaneously acts as a barricade against dendrite formation and a reversible storage material for lithium ions. Therefore, the as-fabricated lithiumion battery using this 3D rectangular channel geometry as an anode material exhibited excellent electrochemical performance in the half-cell as well as in full-cell prototype. In the half-cell configuration, the cell delivered an extraordinary capacity of around $2000 \mathrm{~mA} \mathrm{~h} \mathrm{~g}^{-1}$ and $600 \mathrm{~mA} \mathrm{~h} \mathrm{~g}^{-1}$ at current densities of 150 and $10000 \mathrm{~mA} \mathrm{~g}^{-1}$, respectively. After the rate capability (at various current densities of 150, 200, 500, 1000, 2000, 5000, $10000 \mathrm{~mA} \mathrm{~g}^{-1}$ ) and stability test for 1750 cycles (at a current density of $10000 \mathrm{~mA} \mathrm{~g}^{-1}$ ) the cell retained $80 \%$ of its initial capacity. To the best of our knowledge, this is the only $3 \mathrm{D}$ based anode that exhibited a high capacity of $114 \mu \mathrm{A} \mathrm{h} \mathrm{cm} \mathrm{cm}^{-2}$ and that too at high current density in the full-cell prototype. Finite element-based COMSOL Multiphysics simulations were performed to analyse and establish the ease of Li-ion diffusion in 3D carbon rectangular channels.

\section{Experimental section}

An array of horizontally aligned high aspect ratio 3D rectangular channels of carbon has been designed for fabrication on a penciltraced (graphite-coated) stainless steel substrate. For a 2032-coin cell, a stainless steel current collector of $12 \mathrm{~mm}$ diameter was chosen as a substrate. Further, the surface of the steel substrate was deliberately coarsened with emery paper (paper no:120) and washed thoroughly with DI water and alcohol to remove the impurities. The coarsened surface of the steel substrate was rubbed with a graphite pencil to obtain a uniform graphite layer over it; later it was named a pencil-traced modified stainless steel substrate (PTSS). An epoxy-based negative photoresist, SU-8 2015 (purchased from Microchem Corp., USA) was spin-coated on PTSS at $3000 \mathrm{rpm}$ speed for $30 \mathrm{~s}$ followed by pre-baking at $95{ }^{\circ} \mathrm{C}$ for $2 \mathrm{~min}$ and $30 \mathrm{~s}$ to remove excess solvent. We used a mask-less photolithography approach to fabricate $3 \mathrm{D}$ rectangular patterns from the photo-resist. To attain these 3D patterned structures, a photolithography tool equipped with a UV light source (with a wavelength of $365 \mathrm{~nm}$ ) and an in-built optical grating set-up (Intelligent Micro Patterning, LLC Model no: SF-100 Xpress) were used. A pre-baked photoresist-coated PTSS substrate was subjected to UV exposure (selective exposure) for $25 \mathrm{~s}$ to allow the epoxy to endure polymerization through the cross-linking process. This exposed sample was baked at $95{ }^{\circ} \mathrm{C}$ for 3 min and washed carefully with a commercially available developer solution for $1 \mathrm{~min}$ and $30 \mathrm{~s}$. During this washing process, UV-unexposed areas will be solubilized into the solution and only 3D rectangular microchannels will be left. The patterned sample was further hard-baked at $150{ }^{\circ} \mathrm{C}$ for $5 \mathrm{~min}$ and loaded into a horizontal tubular furnace for pyrolysis. This fabrication procedure is schematically depicted in Fig. 1(a). Before the heating process, the furnace chamber was purged with nitrogen gas at $75 \mathrm{lph}$ for $30 \mathrm{~min}$ and further maintained at a flow rate of $20 \mathrm{lph}$ throughout the pyrolysis process. We followed a two-step pyrolysis approach. Initially, the sample was stabilized at $350{ }^{\circ} \mathrm{C}$ (heating rate of $2{ }^{\circ} \mathrm{C} \mathrm{min}^{-1}$ ) for a dwell time of $30 \mathrm{~min}$. For the carbonization, the temperature of the furnace was later increased to $900{ }^{\circ} \mathrm{C}$ at a $5{ }^{\circ} \mathrm{C} \min ^{-1}$ ramp rate and the sample was maintained at this temperature for $1 \mathrm{~h}$. The sample was collected once the furnace had cooled down to room temperature and it was labeled as 3D rectangular carbon channels on PTSS (3DRC-PTSS). Without any further treatment, the as-prepared 3DRC-PTSS was used as an anode during cell fabrication. The active material mass loading of the $3 \mathrm{D}$ carbon anode was measured to be $0.26 \mathrm{mg} \mathrm{cm}^{-2}$. To ensure the feasibility of electrode fabrication, we further fabricated the electrode with a UV flood exposure photolithography technique using a chrome mask instead of mask-less photolithography.

\subsection{Structural characterization}

The morphological features of the pre-pyrolyzed and post-pyrolyzed patterned samples were studied using an optical microscope (Zeiss AxioCam) and a scanning electron microscope (Phenom ProX, operated at $5 \mathrm{kV}$ ). A 3D optical profiler (NanoMap-D) was used to measure the height distribution of the as-fabricated microchannel arrays. Raman spectra of 3DRC-PTSS were obtained by WiTec Raman spectroscopy with green laser excitation $(532 \mathrm{~nm}$, excitation energy of $2.33 \mathrm{eV}$ ).

\subsection{Electrochemical studies}

2032-Coin cells were assembled inside a glove box $\left(\mathrm{O}_{2}<0.1 \mathrm{ppm}\right.$, $\mathrm{H}_{2} \mathrm{O}<0.1 \mathrm{ppm}$ ) using 3DRC-PTSS as the working electrode and 

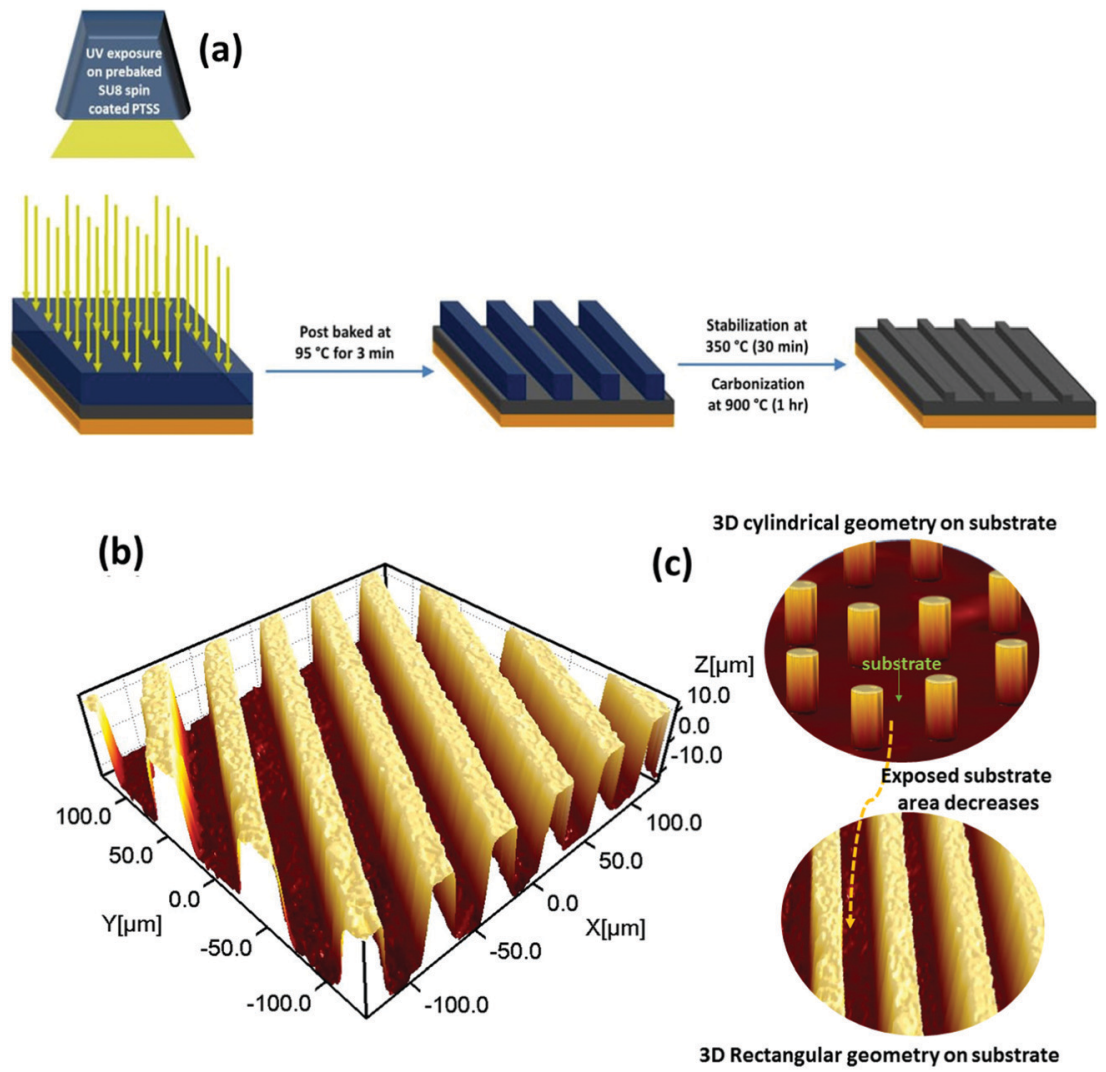

Fig. 1 (a) Schematic representation of the fabrication of 3D-RCPTSS. (b) 3D profiler image of 3D-RCPTSS. (c) Comparison of substrate exposure area of 3D cylindrical structure and 3D rectangular channel.

lithium foil as the counter/reference electrode while for the fullcell fabrication, $\mathrm{LiFePO}_{4}$ was used as the cathode. Whatman glass fiber filter paper was used as a separator and $1 \mathrm{M} \mathrm{LiPF}_{6}$ dissolved in ethylene carbonate (EC) and dimethyl carbonate (DMC) in a ratio of $1: 1(\mathrm{v} / \mathrm{v} \%)$ was used as an electrolyte in the half-cell/fullcell assembly. Further electrochemical tests, cyclic voltammetry (CV), galvanostatic charge-discharge (GCD), and electrochemical impedance analysis (EIS) were conducted on these assembled cells using a Biologic VSP 300 electrochemical work station. GCD was performed in a potential window of $0.01 \mathrm{~V}$ to $3 \mathrm{~V}$ for the halfcell and 2.5 to $3.9 \mathrm{~V}$ for the full cell. The EIS measurement was carried out in the frequency range $0.1 \mathrm{~Hz}$ to $1 \mathrm{MHz}$ by applying a perturbation of $10 \mathrm{mV}$.

\section{Results and discussion}

\subsection{Fabrication of 3D rectangular channels on pencil-traced} SS

For the growth of the 3D rectangular channels, a conventional silicon wafer substrate was replaced by a pencil-traced (graphitecoated) stainless steel current collector (PTSS). The surface of the steel substrate was deliberately coarsened with emery paper to provide good adhesion to the thin layer of coated graphite. This graphite coating can reduce the contact resistance between the active material and the SS substrate while cycling the cell and can also contribute as a storage material (a detailed description has been given in electrochemical studies). The spacing of the rectangular channels is important in determining the total active surface area on the substrate. This directly influences electrochemical performance. If the spacing is larger, then the number of 3D channels is less, which further reduces the areal capacity of the electrode. On the other hand, the minimum spacing between the rectangular channels is determined by the experimental limitations. Considering all the above, the spacing was determined as $20 \mu \mathrm{m}$ for a 3D rectangular channel array. To understand the influence of these 3D rectangular channels on a pencil-traced SS substrate compared to conventional 3D carbon posts on a silicon wafer, the physical and electrochemical properties of this material were scrutinized.

3.2 Profilometry: inspection of the empty spaces between the 3D rectangular structures when compared to cylindrical posts

The exposure of the substrate (current collector) to the electrolyte has to be controlled to achieve a maximum material surface (3D surface) for the electrochemical reaction. Therefore, the 3D structures must be tightly packed with minimum substrate exposure; thereby the direct contact of lithium ions with the substrate can be avoided. Fig. 1(b) depicts the three-dimensional profilometry of the equally spaced rectangular geometry of the fabricated 3D channels. The structure exhibited uniformity with straight walls and an excellent edge profile. The average height of the channel in 3D RC-PTSS is $15 \pm 2 \mu \mathrm{m}$ and the width and 
spacing between the rectangular channels are $20 \pm 5 \mu \mathrm{m}$. The importance of this geometry is that the $3 \mathrm{D}$ rectangular channel reduces the exposure of the substrate (current collector) to the electrolyte compared to carbon posts. The maximum area of the circular substrate is covered by this $3 \mathrm{D}$ geometry and the remaining exposed area is graphite coated. Therefore, the direct exposure of the SS substrate area to the electrolyte is eliminated compared to the cylindrical carbon post geometry on an SS/silicon substrate. Fig. 1(c) schematically represents the reduction in substrate exposure.

\subsection{SEM and optical imaging}

Optical microscope and SEM images, as shown in Fig. 2(a and b), provide a panoramic view of the 3D RC-PTSS. It shows an array of uniform 3D channel structures with consistency in channel width and spacing between channels. The width and spacing between the 3D channels are labeled in Fig. 2(a). The color contrast in the optical image (Fig. 2(a)) and SEM image (inset of Fig. 2(b)) verifies the 3D projection of the rectangular channels on the substrate. The obtained 3D pattern without any distortion shows that the penciled graphite layer could provide a good adhesive surface for the growth of the 3D structures. SEM and optical images provide a clear visualization of the grown 3DRC-PTSS. After cycling, the cell was dissassembled and the electrode was examined under SEM to verify the structural integrity of the 3D rectangular channels. Fig. S1 $(\mathrm{ESI} \dagger)$ reveals that the $3 \mathrm{D}$ rectangular channel structure is stable and only a minor distortion was noticed.

\subsection{Raman spectroscopic analysis: scrutiny on substrate carbon and SU-8 derived carbon}

To identify the nature of SU-8 derived carbon and pencil-traced carbon on the SS substrate, Raman spectra were collected from PTSS (graphite-coated area) and the top surface of the 3D RC-PTSS, respectively (Fig. 2(c)). The top surface of 3D RC-PTSS

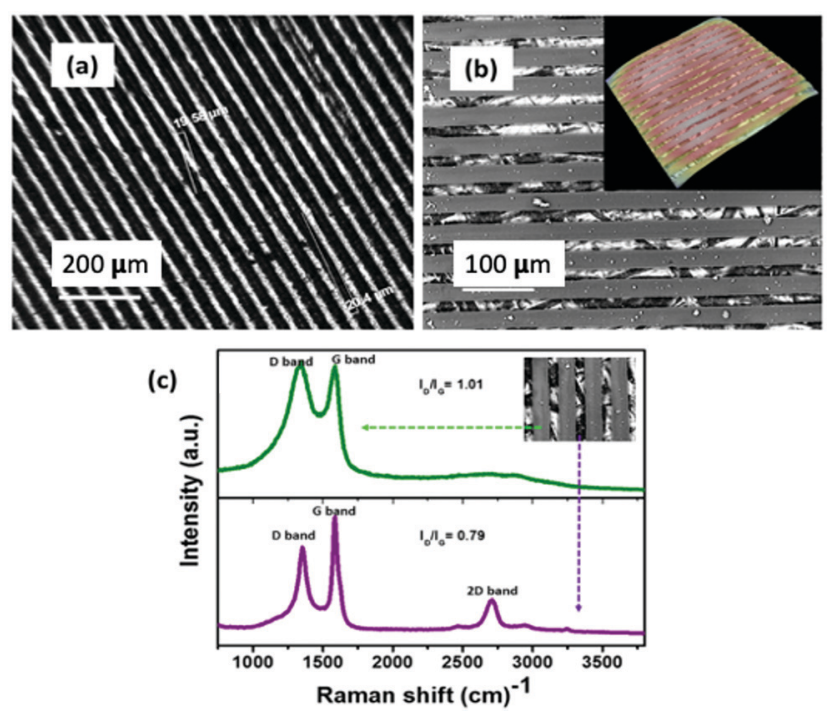

Fig. 2 (a) Optical image of 3D-RCPTSS. (b) SEM image of 3D-RCPTSS; inset is the 3D constructed SEM image. (c) Raman spectra of 3D-RCPTSS.
(SU-8 derived carbon) exhibits two characteristic peaks at $\sim 1330 \mathrm{~cm}^{-1}$ and $\sim 1590 \mathrm{~cm}^{-1}$ representing the $A_{1 \mathrm{~g}}$ symmetry of disordered graphite and the $\mathrm{E}_{2 \mathrm{~g}}$ symmetry mode associated with the in-plane stretching of the $\mathrm{sp}^{2}$ bonded carbon atoms, respectively. ${ }^{22,23}$ These partially superimposed D and $\mathrm{G}$ bands with an $I_{\mathrm{D}} / I_{\mathrm{G}}$ ratio $\sim 1$ indicate the degree of disorder with a glassy carbon nature. ${ }^{11}$ While the Raman spectrum of penciled carbon (graphite-coated surface) shows well-defined D and G as well as 2D bands at $\sim 1350 \mathrm{~cm}^{-1}, \sim 1590 \mathrm{~cm}^{-1}$, and $\sim 2590 \mathrm{~cm}^{-1}$, respectively, which are the characteristic peaks of graphitic carbon. The $I_{\mathrm{D}} / I_{\mathrm{G}}$ ratio of $\sim 0.79$ also indicates the more graphitic nature of pencil-traced carbon. Therefore, we can say that the fabricated anode (3D-RCPTSS) is a combination of glassy carbon and graphitic carbon.

\subsection{Electrochemical properties}

We identified the possible issues of a conventional 3D cylindrical carbon post electrode on an SS/silicon substrate (current collector) related to the electrochemical performance of the cell. The main issues are (1) irreversible capacity, ${ }^{24}$ (2) limited lithiumion storage, (3) inefficient utilization of carbon pillars, and
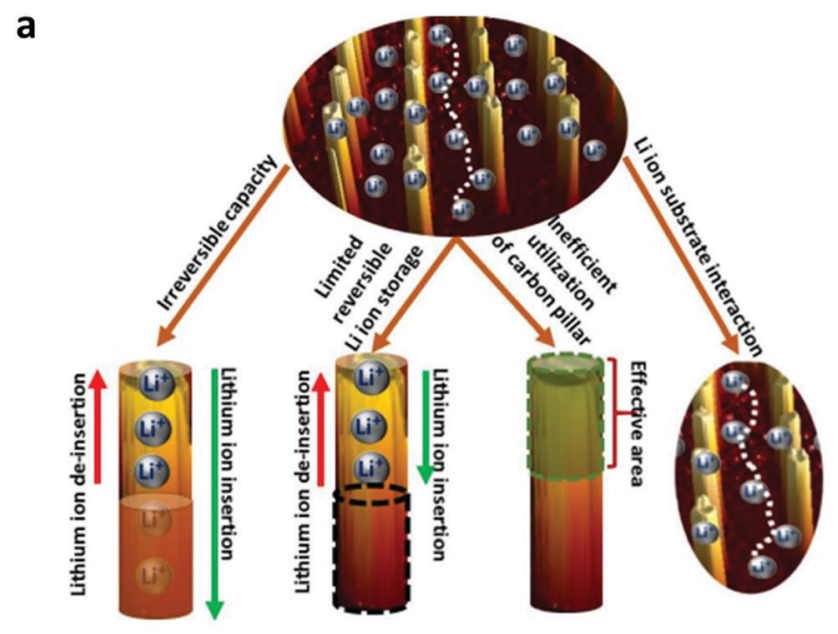

b

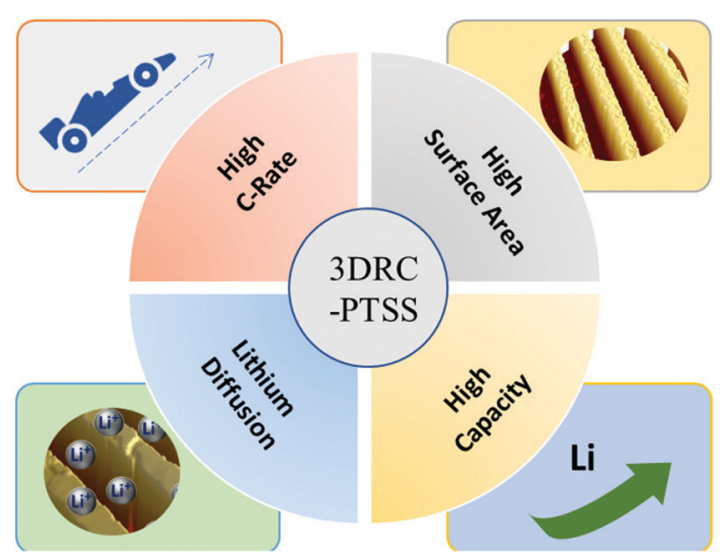

Fig. 3 (a) Schematic representation of the issues related to a conventional cylindrical carbon post electrode. (b) Advantages of 3D microelectrodes channels over planar electrodes. 
(4) lithium-ion-substrate interaction (schematically represented in Fig. 3(a) and (b)). Due to these severe setbacks, the cell miserably ended up in short circuiting or malfunctioning (a falling of the Coulombic efficiency of the cell). Therefore, fabricating 3D rectangular channels over PTSS instead of 3D cylindrical carbon posts aids in utilizing these 3D structures to their full potential as anode materials. The detailed electrochemical studies of 3D RC-PTSS, as described below, address all the issues related to conventional $3 \mathrm{D}$ pillars on silicon/SS substrates.

3.5.1 Reversible lithium-ion storage in 3D RC-PTSS. To understand the reversible lithium-ion storage capability of 3D glassy carbon rectangular channels on a pencil-traced SS current collector as an anode material, coin cells were assembled using $\mathrm{LiPF}_{6}$ as an electrolyte and lithium foil as a counter/reference electrode. Cyclic voltammetry (CV) measurement was employed on the assembled cell in the potential window of 0.01 to $3 \mathrm{~V} v s$. $\mathrm{Li} / \mathrm{Li}^{+}$at a scan rate of $0.1 \mathrm{mV} \mathrm{s}{ }^{-1}$. The anodic and cathodic peaks are observed at 0.16, 0.26, and $0.05 \mathrm{~V}$, respectively (Fig. 4(a)). The large hysteresis of the first cycle CV (Fig. 4(a)) is attributed to the formation of a passive SEI layer. ${ }^{25}$ This SEI layer is formed at the electrode-electrolyte interface by electrolyte decomposition. This passive layer stabilizes the electrode in subsequent cycles by further preventing any solvent molecules from co-intercalation into the carbon structures. ${ }^{26,27}$ The repeatability of these anodic and cathodic peaks in all cycles without hysteresis loss in further cycles represents a stable reversible lithium-ion storage capacity of the anode.

Moreover, the distinct peak positions and their repeatability in the anodic scan represent the lithium-ion storage in the pencil lead graphite by the intercalation/de-intercalation method. These peaks are due to the staged transformation of lithium-graphite intercalation compounds of $\mathrm{LiC}_{24}, \mathrm{LiC}_{12}$, and $\mathrm{LiC}_{6}$ at the PTSS base of 3DRC-PTSS, respectively. ${ }^{28-30}$ This is further clarified by the CV of the cell with only PTSS (graphitecoated SS) as the anode presented in Fig. S2 (ESI $\dagger$ ). The CV analysis shows that 3D RC-PTSS has a larger electrochemical surface area than that of PTSS alone, which emphasizes lithium-ion storage in the glassy carbon. It is also proof of reversible lithium-ion storage in penciled graphite as well as 3D glassy carbon rectangular channels in 3DRC-PTSS. This result is evidence for the direct interaction of lithium ions with the substrate material through the embedded space between the 3D structures. In other words, if the SS substrate (current collector) is (a)

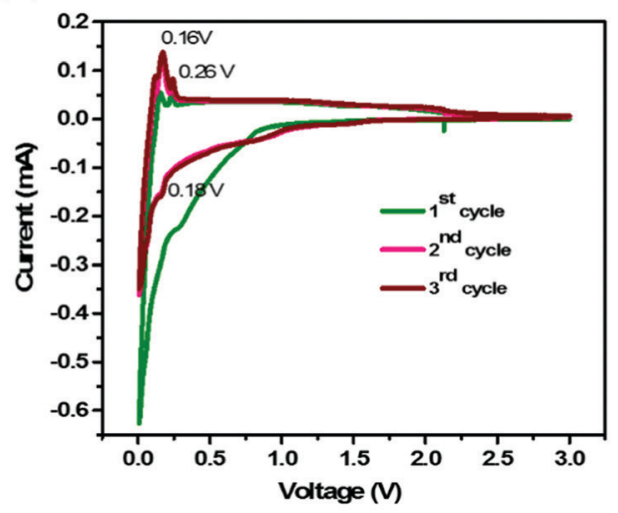

(b)

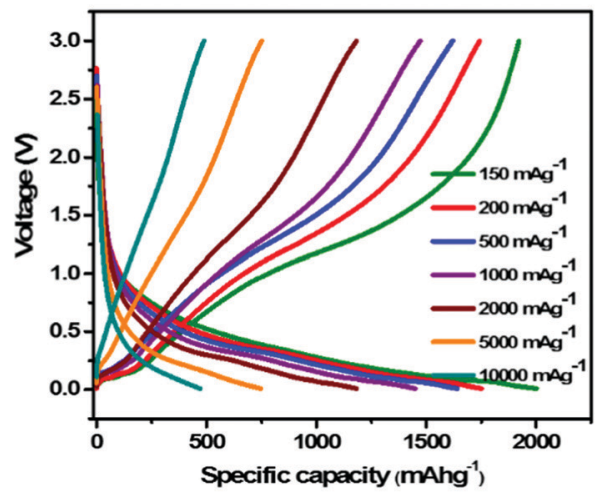

(c)

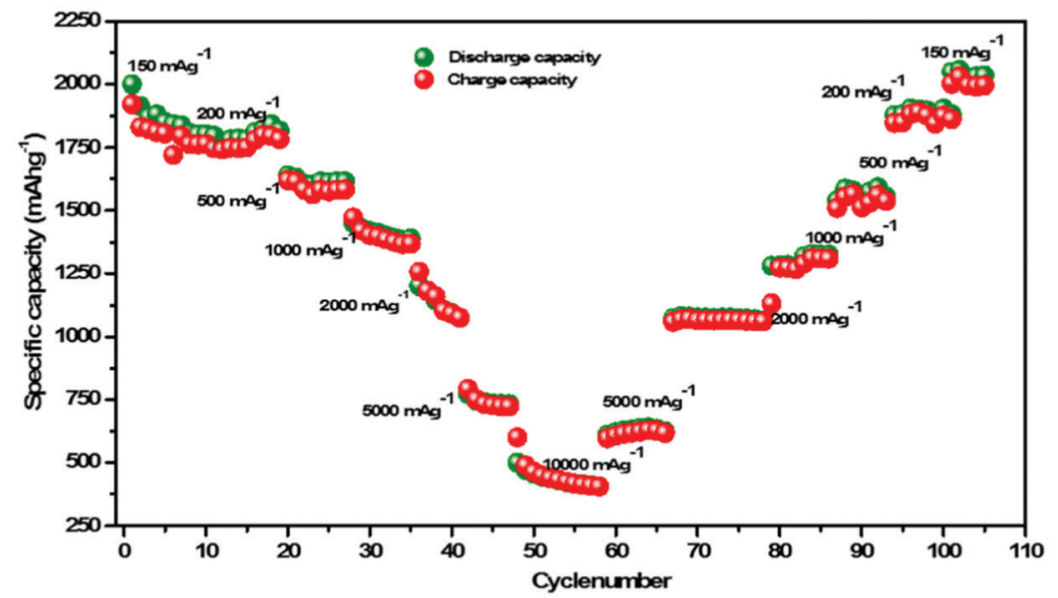

Fig. 4 (a) Cyclic voltammetry of 3DRC-PTSS at scan rate of $0.1 \mathrm{mV} \mathrm{s}^{-1}$ in a voltage window of 0.01 to $3 \mathrm{~V}$. (b) GCD of 3DRC-PTSS at different current rates. (c) Rate capability of 3DRC-PTSS at different current rates: 150, 200, 500, 1000, 2000, 5000 and $10000 \mathrm{~mA} \mathrm{~g}^{-1}$. 
not pencil traced with graphite, there will be a direct interaction of lithium ions with the SS substrate (current collector) that can cause dendrite formation and ultimately shorting of the battery.

3.5.2 Substrate (current collector) modification prevents malfunctioning of the battery. The other serious concern is the proper functioning of the battery without diminishing Coulombic efficiency. This will be possible only when the electrode material shows a high level of reversibility in lithium-ion transfer. Therefore, it is necessary to grow the 3D structures with minimum substrate exposure, and also the exposed substrate area should be a reversible lithium-ion storage material to access a high electrode surface area for a reversible electrochemical reaction. This is one of the important findings in the present work which we could not find in the reported literature, i.e., utilization of the substrate (current collector) area exposed to the electrolyte, for reversible lithiumion storage to avoid malfunctioning of the battery or shorting of the battery. Herein due to pencil-traced graphite layer modification, the direct interaction of lithium ions with the SS substrate is prevented. Moreover, it plays a vital role in enhancing the capacity of the battery along with compact rectangular channels. The reversibility of pencil lead graphite in a composite in lithium-ion storage was recently reported by our group. ${ }^{31}$ To prove our point further, GCD has been conducted with only PTSS (graphite-coated SS) as the anode (Fig. S3, ESI $\dagger$ ). Cell stability and capacity retention are important criteria for understanding the proper functioning of the battery without any malfunctioning or shorting of the battery due to large irreversible capacity and lithium dendrite formation. In this respect, for vivid confirmation, the cell was cycled at different current densities ranging from $150 \mathrm{~mA} \mathrm{~g}^{-1}$ to as high as $10000 \mathrm{~mA} \mathrm{~g}^{-1}$ (Fig. 4(b)). The charging and discharging of the battery at a low current rate provide information regarding the maximum utilization of the anode material as well as the efficiency of the battery to deliver current to the load. The cell cycled at different current densities 150, 200, 500, 1000, 2000, 5000 and $10000 \mathrm{~mA} \mathrm{~g}^{-1}$ exhibited capacities of 2000, 1750, 1645, 1451, 1183, 746 and $484 \mathrm{~mA} \mathrm{~h} \mathrm{~g}^{-1}$, respectively. The capacity retention of $2034 \mathrm{~mA} \mathrm{~h} \mathrm{~g}^{-1}$ at $150 \mathrm{~mA} \mathrm{~g}^{-1}$ after cycling at $10000 \mathrm{~mA} \mathrm{~g}^{-1}$ shows the applicability of the cell at a low current rate as well as a high current rate (Fig. 4(c)). This electrochemical response shows that there is no malfunctioning of the battery either at high or at low current densities due to the substrate protection from lithium plating by the pencil lead graphite coating. (a)

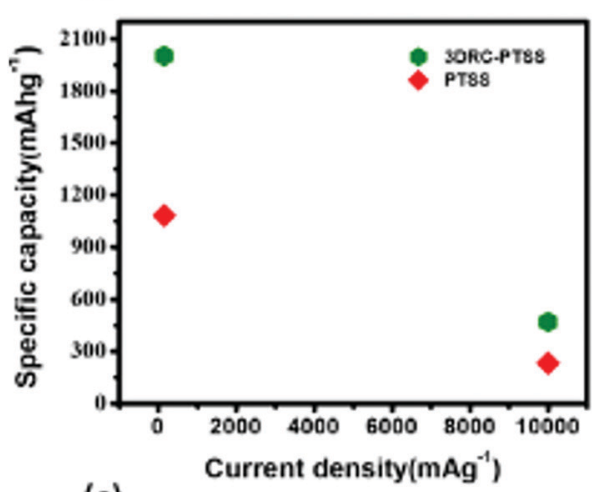

(c) (b)

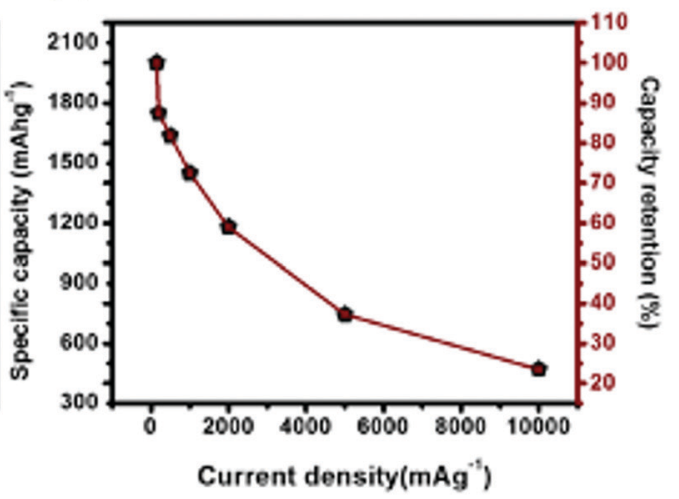

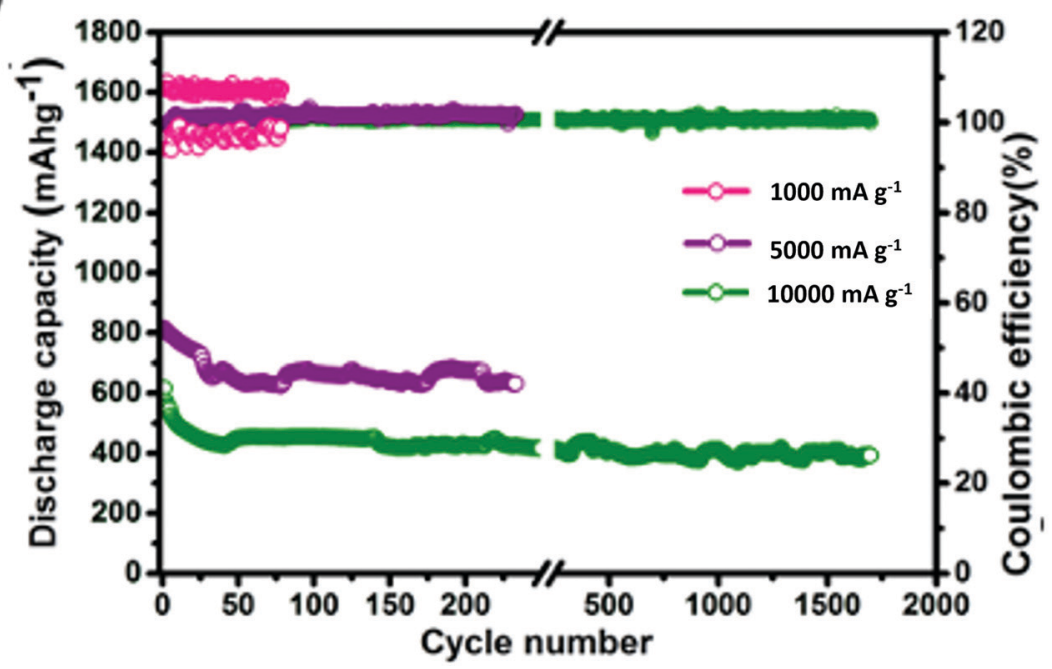

Fig. 5 (a) Comparison of 3DRC-PTSS with PTSS alone. (b) Capacity retention of 3DRC-PTSS at high current density. (c) Stability test of 3DRC-PTSS at different current rates: 1000,5000 and $10000 \mathrm{~mA} \mathrm{~g}^{-1}$. 
3.5.3 Capacity enhancement due to $3 \mathrm{D}$ rectangular structures on PTSS. Fig. 5(a) demonstrates the capacity enhancement of 3DRC-PTSS in comparison with PTSS alone (graphitecoated SS), and the results are compared with carbon posts on SS, and conventional carbon posts and other 3D geometries on a silicon wafer ${ }^{11,14,32,33}$ (Table S1, ESI $\dagger$ ). 3DRC-PTSS exhibited capacities of 2000 and $484 \mathrm{~mA} \mathrm{~h} \mathrm{~g}^{-1}$ at 150 and $10000 \mathrm{~mA} \mathrm{~g}^{-1}$, respectively, whereas PTSS showed capacities of 1080 and $228 \mathrm{~mA} \mathrm{~h} \mathrm{~g}^{-1}$, respectively. In addition, Fig. 5(b) shows that when the current increases from 150 to $10000 \mathrm{~mA} \mathrm{~g}^{-1}$ (almost a 67 times increment in current density), the cell could retain $25 \%$ of its capacity. This observation undeniably proves the role of 3D RC structures in the fast-reversible lithium-ion storage mechanism. Further, compared to the reported capacity values and cycle life (550 $\left.\mathrm{mA} \mathrm{h} \mathrm{g}{ }^{-1}\right)$ at $0.1 \mathrm{C}$ (100 cycles), ${ }^{32} 220 \mathrm{~mA} \mathrm{~h} \mathrm{~g}^{-1}$ at $0.5828 \mathrm{~mA}$ (9 cycles) ${ }^{33} \sim 200 \mathrm{~mA} \mathrm{~h} \mathrm{~g}{ }^{-1}$ at $76.4 \mu \mathrm{A} \mathrm{cm} \mathrm{cm}^{-2}$ (6 cycles), ${ }^{14} 596 \mathrm{~mA} \mathrm{~h} \mathrm{~g}^{-1}$ at $37.2 \mathrm{~mA} \mathrm{~g}^{-1}$ (160 cycles), ${ }^{11}$ the cylindrical 3D structures on penciled SS reported a capacity of $538 \mathrm{~mA} \mathrm{~h} \mathrm{~g}^{-1}$ at $500 \mathrm{~mA} \mathrm{~g}^{-1}\left(100\right.$ cycles $\left.^{34}\right)$. For further confirmation, cylindrical carbon structures were fabricated on SS and penciled SS and the electrochemical data are given in Fig. S5a and $b$ (ESI $\dagger$ ), respectively. The cell exhibited capacities of 100 and $900 \mathrm{~mA} \mathrm{~h} \mathrm{~g}^{-1}$, respectively. When compared to a previous report ${ }^{11}$ as well as carbon posts on SS and pencil-traced SS, we observed that 3DRC-PTSS showed its supremacy both in capacity and in capacity retention. This could be due to the large surface area that is accessible for lithium-ion storage with the shortest diffusion path while cycling the cell.

The rate capability test signifies the ability of 3DRC-PTSS to work equally well in a higher current density range. Therefore the stability test of the cell was performed at 1000, 5000, and $10000 \mathrm{~mA} \mathrm{~g}^{-1}$ for 150,250 , and 1750 cycles, respectively (Fig. 5(c)). The cell could deliver a capacity of $\sim 400 \mathrm{~mA} \mathrm{~h} \mathrm{~g}^{-1}$ at $10000 \mathrm{~mA} \mathrm{~g}^{-1}$ (after 1750 cycles), $700 \mathrm{~mA} \mathrm{~h} \mathrm{~g}^{-1}$ at $5000 \mathrm{~mA} \mathrm{~g}^{-1}$ (after 250 cycles), and $1400 \mathrm{~mA} \mathrm{~h} \mathrm{~g}{ }^{-1}$ at $1000 \mathrm{~mA} \mathrm{~g}^{-1}$ (after 150 cycles), respectively. The long cyclic life of the battery at different current densities without shorting or malfunctioning substantiates the potential of 3DRC-PTSS as anode material.

3.5.4 Electrochemical impedance as a supporting study for the storage mechanism. To further examine the electrochemical properties of the cell in terms of electrochemical impedance, EIS measurement was carried out on the same cell after stability testing. Fig. 6(a) represents the EIS profile of 3DRCPTSS; the obtained EIS data fitted by an equivalent circuit are shown in Fig. S4 (ESI $\dagger$ ). The equivalent circuit consists of series and parallel combinations of resistors and constant-phase elements. $R_{\mathrm{E}}$ is the equivalent series resistance that indicates the resistance involved in the electrolyte, and the obtained $R_{\mathrm{E}}$ value is $5.4 \Omega$ after fitting.

Similarly, $R_{\mathrm{SEI}}$ and $\mathrm{CPE}_{\mathrm{SEI}}$ indicate the impedance due to SEI layer formation, and $R_{\mathrm{CT}}$ and $\mathrm{CPE}_{\mathrm{CT}}$ measure the impedance (a)

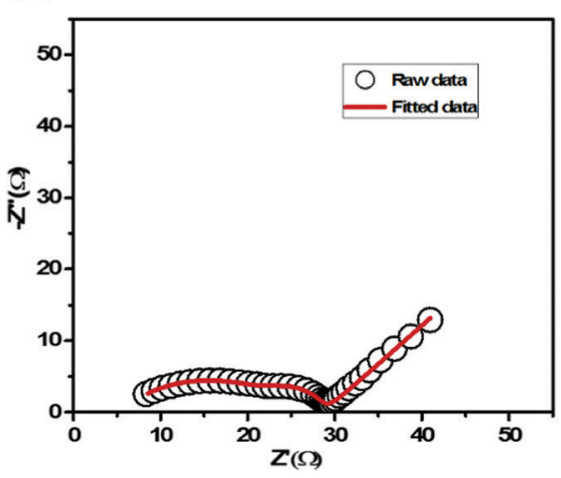

(c)

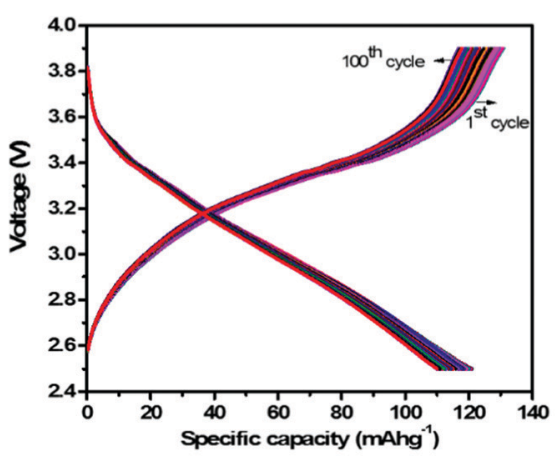

(b)

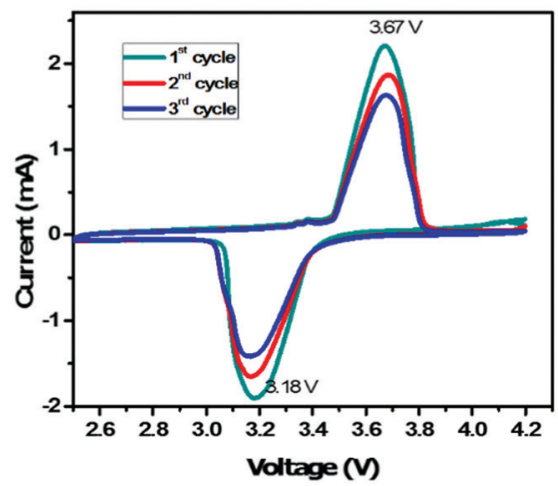

(d)

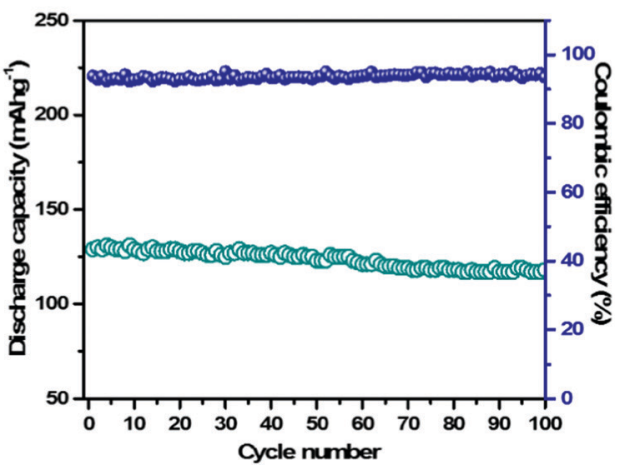

Fig. 6 (a) EIS analysis of 3DRC-PTSS in the frequency range $0.1 \mathrm{~Hz}$ to $1 \mathrm{MHz}$. (b) Cyclic voltammetry on the full-cell prototype in the potential window 2.5 to $4.2 \mathrm{~V}$ at $0.1 \mathrm{mV} \mathrm{s}^{-1}$. (c) GCD of the full cell. (d) Stability test of the full cell at $100 \mu \mathrm{A}$ in the potential window 2.5 to $3.9 \mathrm{~V}$. 
involved in the charge transfer reaction. ${ }^{35-37}$ The calculated $R_{\mathrm{SEI}}$ and $R_{\mathrm{CT}}$ values are $19 \Omega$ and $4.5 \Omega$, respectively, which implies that the cell provides minimum resistance for charge transfer. The SEI layer resistance is higher than the charge transfer resistance. This may be due to the resistance involved due to layer formation on the glassy carbon channels and penciled graphite. These impedance values are negligibly small when compared to the reported impedance values in the range of hundreds and thousands of ohms and clearly show the advantage of the 3DRC-PTSS electrode over conventional silicon substrate grown 3D structures. ${ }^{14,15}$ The faster reaction kinetics of the cell with capacity retention reveals that SEI acts as a good passivation layer for lithium ions. The appearance of a small diffusion line represented by a constant phase element (semiinfinite diffusion) further proves that the lithium-ion diffusion process is reasonably good.

3.5.5 Full-cell study reveals the proficiency of 3DRC-PTSS as anode for commercial batteries. The ultimate goal of developing an anode material is to check the efficiency of the material in a full cell. Therefore, to evaluate the material a prototype full-cell has been fabricated using carbon-coated $\mathrm{LiFePO}_{4}$ as a cathode material and 3DRC-PTSS as an anode. To avoid lithium deficiency while cycling the cell, the weight of the cathode material is balanced according to the anode material. The cyclic voltammetry and galvanostatic chargedischarge measurements were performed in the potential window
2.5 to $3.9 \mathrm{~V}$ (Fig. 6(b and c)). The cell showed an oxidation peak at $3.67 \mathrm{~V}$ and a reduction peak at $3.18 \mathrm{~V}$; the difference between the oxidation and reduction peaks is $0.49 \mathrm{~V}$, showing the good reversibility of the cell. The cell delivered an initial capacity of $122 \mathrm{~mA} \mathrm{~h} \mathrm{~g}{ }^{-1}\left(114 \mu \mathrm{A} \mathrm{h} \mathrm{cm}{ }^{-2}\right)$ at a current $100 \mu \mathrm{A}$ with Coulombic efficiency of $94.6 \%$. After cycling the cell for 100 cycles, the cell retained a discharge capacity of $110 \mathrm{~mA} \mathrm{~h} \mathrm{~g}^{-1}\left(107.6 \mu \mathrm{A} \mathrm{h} \mathrm{cm} \mathrm{cm}^{-2}\right)$. These values are almost eleven times higher than that reported for $3 \mathrm{D}$ carbon posts based on a full cell $\left(10.6 \mu \mathrm{A} \mathrm{h} \mathrm{cm}{ }^{-2}\right) .{ }^{4}$ The capacity of $\sim 107 \mu \mathrm{A} \mathrm{h}$ at $100 \mu \mathrm{A}$ after 100 cycles shows the potency of this material in practical use (Fig. 6(d)).

\subsection{Li-ion diffusion model}

The finite element method (FEM) based diffusion model on the COMSOL simulation platform was carried out to examine the variation in Li-ion concentration across the $3 \mathrm{D}$ carbon rectangular channels with respect to time. To perform the Li-ion diffusion studies, we considered two cases: (i) 3D morphology of rectangular channels and (ii) the equivalent volume of flat (2D) electrodes. Further, a comprehensive comparative study for both cases was done to investigate the concentration gradients, as depicted in Fig. 7. In this study, we modeled the lithium-ion diffusion across the electrode by using Fick's Second Law of diffusion, as described in eqn (1). ${ }^{38}$ Here, the preliminary assumption is that the change in Li-ion
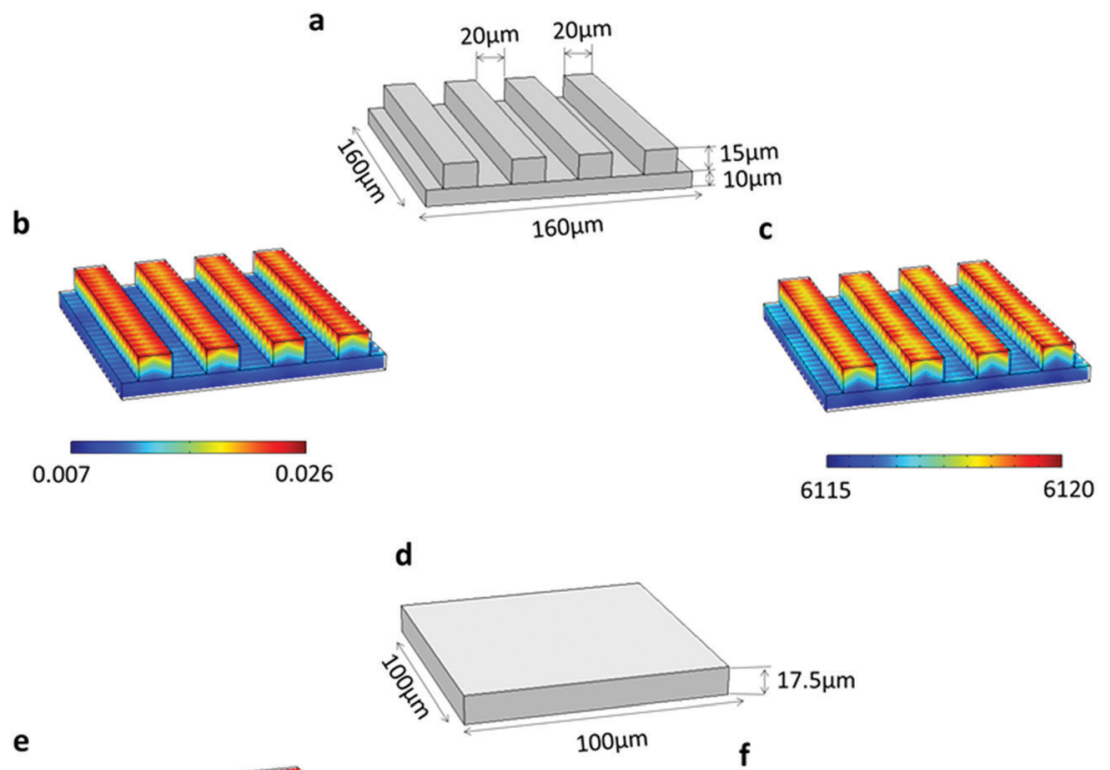

e

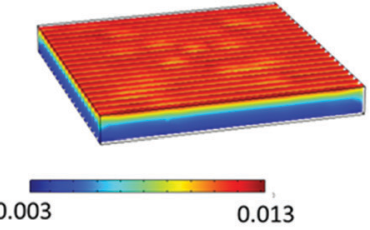

f

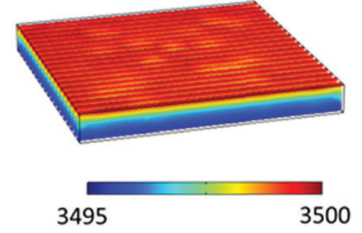

Fig. 7 Li diffusion model: (a) 3D microelectrode geometry used to construct the FEM model. (b) Li-ion distribution ( $\mathrm{mol} \mathrm{m}^{-3}$ ) in a 3D carbon rectangular channel after $0.1 \mathrm{~s}$. (c) Li-ion distribution $\left(\mathrm{mol} \mathrm{m}^{-3}\right.$ ) in a 3D carbon rectangular channel after $60 \mathrm{~min}$. (d) Model geometry for the flat electrode used to construct the FEM model. (e) Li-ion distribution $\left(\mathrm{mol} \mathrm{m}^{-3}\right.$ ) in a flat electrode morphology after $0.1 \mathrm{~s}$. (f) Li-ion distribution $\left(\mathrm{mol} \mathrm{m}^{-3}\right.$ ) in a flat electrode morphology after $60 \mathrm{~min}$. 
concentration is mainly due to the concentration gradient and the other term (migration and source reaction) is negligible.

$$
\frac{\partial c_{\mathrm{Li}}}{\partial t}=\nabla \cdot\left(D_{\mathrm{Li}} \nabla c_{\mathrm{Li}}\right)
$$

In eqn (1), $D_{\mathrm{Li}}$ is Li-ion diffusivity $\left(\mathrm{m}^{2} \mathrm{~s}^{-1}\right)$ and $C_{\mathrm{Li}}$ represents the concentration of $\mathrm{Li}$-ions $\left(\mathrm{mol} \mathrm{m}^{-3}\right)$ at time $t$.

In order to make the conditions of the simulation study closer to the experimental, the following measures were taken. (i) A more accurate replica of model geometry was constructed (Fig. 7(a)) based on the optical profiler data (Fig. 1(b)) of the real system. (ii) The experimental current density was used to calculate the flux boundary condition, as given in eqn (2). ${ }^{39,40}$

$$
D_{\mathrm{Li}} \frac{\partial c_{\mathrm{Li}}}{\partial x}=-\frac{i_{\mathrm{app}}}{n F}
$$

where $i_{\text {app }}$ denotes the applied current density $\left(\mathrm{A} \mathrm{m}^{-2}\right)$ at the cell level, $F$ is the Faraday constant, and $n$ is the number of electrons involved in the electrochemical reaction.

The effective diffusion coefficient of 3D carbon rectangular channels was calculated using EIS data, as discussed in the literature. $^{41,42}$ The calculated diffusion coefficient for the $3 \mathrm{D}$ carbon rectangular channels electrode is $1.44 \times 10^{-8} \mathrm{~m}^{2} \mathrm{~s}^{-1}$. Fig. 7(b) shows the Li-ion concentration $\left(0.026 \mathrm{~mol} \mathrm{~m}^{-3}\right)$ in a $3 \mathrm{D}$ carbon rectangular channel after $0.1 \mathrm{~s}$ and its increase to $6120 \mathrm{~mol} \mathrm{~m}^{-3}$ after $60 \mathrm{~min}$ (Fig. 7(c)). The change in Li-ion concentration of the $2 \mathrm{D}$ flat electrode with an equivalent volume of $3 \mathrm{D}$ carbon rectangular channels was also modeled, as shown in (Fig. 7(d)). After $60 \mathrm{~min}$, Li-ion concentration in a 2D flat electrode increased from $0.013 \mathrm{~mol} \mathrm{~m}^{-3}$ (Fig. 7(e)) to $3500 \mathrm{~mol} \mathrm{~m}^{-3}$ (Fig. 7(f)). The maximum Li-ion concentration after $60 \mathrm{~min}$ in both cases was found to be $6120 \mathrm{~mol} \mathrm{~m}^{-3}$ and $3500 \mathrm{~mol} \mathrm{~m}^{-3}$ for 3D rectangular channels and 2D flat electrode morphology, respectively. This clearly indicates that the 3D carbon rectangular channels enabled effective Li-ion diffusion compared to the $2 \mathrm{D}$ flat electrode.

\section{Conclusions}

We introduced a unique three-dimensional rectangular channel geometry on a pencil-traced stainless steel current collector to avoid the malfunctioning of the battery due to direct contact of lithium ions with the SS substrate as well as to maximize the capacity with a minimum lithium-ion diffusion path length and minimum substrate exposure. We observed the successful growth of 3D structures on pencil-traced SS due to the excellent adhesion of SU-8 polymer with the graphite layer, which after pyrolysis yielded 3D carbon rectangular channels without any structural damage. These rectangular geometries provided a larger surface area for the electrochemical reaction by decreasing the direct substrate exposure to the electrolyte and, therefore, showed its advantages over cylindrical carbon posts on the substrate, which are typically shown as 3D electrodes in the literature. From a battery perspective, 3DRC-PTSS exhibited outstanding electrochemical performance in half-cell as well as in full-cell configurations. The cell showed excellent lithiumion storage characteristics and, more importantly, in lower as well as higher current densities. At $150 \mathrm{~mA} \mathrm{~g}^{-1}$, the cell exhibited a reversible capacity of $2000 \mathrm{~mA} \mathrm{~h} \mathrm{~g}^{-1}$ and $\sim 400 \mathrm{~mA} \mathrm{~h} \mathrm{~g}^{-1}$ at as high as $10 \mathrm{~A} \mathrm{~g}^{-1}$ current density. This could be due to the synergetic effect of pencil-traced graphite along with the $3 \mathrm{D}$ carbon structures. Also, the full-cell study proves its potential to work at a high current by retaining a capacity of $110 \mathrm{~mA} \mathrm{~h} \mathrm{~g}$ $\left(107.6 \mu \mathrm{Ah} \mathrm{cm}^{-2}\right)$ at $100 \mu \mathrm{A}$. The outcome of this work shows the plausible use of this anode material for the development of next-generation lithium-ion batteries.

\section{Conflicts of interest}

There are no conflicts to declare.

\section{Acknowledgements}

We acknowledge the financial support received from Ministry of Human Resources Development and Department of Heavy Industries, Govt. of India under IMPRINT scheme (Project 7035) to carry out this work.

\section{References}

1 C. Han, H. Li, Y. Li, J. Zhu and C. Zhi, Nat. Commun., 2021, 12, 2400.

2 C. Wang, L. Taherabadi, G. Jia, S. Kassegne, J. V. Zoval and M. J. Madou, MEMS, MOEMS, and Micromachining, 2004, vol. 5455, p. 295.

3 C. Wang, L. Taherabadi, G. Jia, M. Madou, Y. Yeh and B. Dunn, Electrochem. Solid-State Lett., 2004, 7, A435-A438.

4 H. S. Min, B. Y. Park, L. Taherabadi, C. Wang, Y. Yeh, R. Zaouk, M. J. Madou and B. Dunn, J. Power Sources, 2008, 178, 795-800.

5 B. Pramanick, M. Vazquez-Pinon, A. Torres-Castro, S. O. Martinez-Chapaa and M. Madou, Mater. Today Proc., 2018, 5, 9669-9682.

6 P. S. Ginestra, M. Madou and E. Ceretti, Precis. Eng., 2019, 55, 137-143.

7 C. Wang, R. Zaouk, B. Y. Park and M. J. Madou, Int. J. Manuf. Technol. Manage., 2008, 13, 360.

8 H. A. Rouabah, B. Y. Park, R. B. Zaouk, H. Morgan, M. J. Madou and N. G. Green, J. Micromech. Microeng., 2011, 21(3), 035018.

9 J. I. Heo, D. S. Shim, G. T. Teixidor, S. Oh, M. J. Madou and H. Shin, J. Electrochem. Soc., 2011, 158, J76.

10 R. R. Kamath and M. J. Madou, Anal. Chem., 2014, 86, 2963-2971.

11 S. Mamidi, M. Kakunuri and C. S. Sharma, ECS Trans., 2018, 85, 21-27.

12 S. Jiang, F. Wang, X. Tan, J. Lin, G. Liao, Z. Tang, T. Shi and L. Qian, Electrochim. Acta, 2019, 303, 323-328.

13 Y. Wang, L. Pham, G. P. S. de Vasconcellos and M. Madou, J. Power Sources, 2010, 195, 4796-4803. 
14 G. T. Teixidor, R. B. Zaouk, B. Y. Park and M. J. Madou, J. Power Sources, 2008, 183, 730-740.

15 F. Galobardes, C. Wang and M. Madou, Diamond Relat. Mater., 2006, 15, 1930-1934.

16 C. S. Sharma, H. Katepalli, A. Sharma and M. Madou, Carbon, 2010, 49, 1727-1732.

17 S. Sharma, A. Sharma, Y. K. Cho and M. Madou, ACS Appl. Mater. Interfaces, 2012, 4, 34-39.

18 L. Zhang, X. Qin, S. Zhao, A. Wang, J. Luo, Z. L. Wang, F. Kang, Z. Lin and B. Li, Adv. Mater., 2020, 32, 1908445.

19 L. Zhang, T. Shi, S. Xi, D. Liu, Z. Tang, X. Li and W. Lai, Thin Solid Films, 2011, 520, 1041-1047.

20 Y. Gao, T. Shi, H. Zheng, Z. Tang and Q. Xia, Thin Solid Films, 2014, 550, 156-163.

21 Y. Gao, T. Shi, Z. Tang, S. Jiang and Q. Xia, Appl. Surf. Sci., 2014, 313, 687-691.

22 R. J. Nemanich and S. A. Solin, Phys. Rev. B: Condens. Matter Mater. Phys., 1979, 20, 392-401.

23 S. Reich and C. Thomsen, Philos. Trans. R. Soc. A Math. Phys. Eng. Sci., 2004, 362, 2271-2288.

24 W. Xing and J. R. Dahn, J. Electrochem. Soc., 1997, 144, 1195-1201.

25 P. Verma, P. Maire and P. Novak, Electrochim. Acta, 2010, 55, 6332-6341.

26 M. Winter, J. O. Besenhard, M. E. Spahr and P. Novák, Adv. Mater., 1998, 10, 725-763.

27 J. O. Besenhard, M. Winter, J. Yang and W. Biberacher, J. Power Sources, 1995, 54, 228-231.

28 M. D. Levi and D. Aurbach, J. Electroanal. Chem., 1997, 421, 79-88.
29 F. Ding, W. Xu, D. Choi, W. Wang, X. Li, M. H. Engelhard, X. Chen, Z. Yang and J.-G. G. Zhang, J. Mater. Chem., 2012, 22, 12745-12751.

30 M. Yoshio, H. Wang, K. Fukuda, Y. Hara and Y. Adachi, J. Electrochem. Soc., 2000, 147, 1245.

31 S. Mamidi, A. Gangadharan and C. S. Sharma, Electrochim. Acta, 2019, 310, 222-229.

32 S. Choi, J. I. Lee and S. Park, J. Mater. Chem., 2012, 22, 22366-22369.

33 C. Wang, G. Jia, L. H. Taherabadi and M. J. Madou, J. Microelectromech. Syst., 2005, 14, 348-358.

34 S. Mamidi, A. Gangadharan, A. D. Pathak, T. N. Rao and C. S. Sharma, ACS Appl. Energy Mater., 2020, 4(1), 545-553.

35 Z. Favors, H. H. Bay, Z. Mutlu, K. Ahmed, R. Ionescu, R. Ye, M. Ozkan and C. S. Ozkan, Sci. Rep., 2015, 5, 1-7.

36 G. Ananya, N. Pranati and S. Ramaprabhu, Int. J. Hydrogen Energy, 2016, 41, 3974-3980.

37 S. Ramaprabhu, A. Gangadharan and R. Sripada, J. Mater. Chem. A, 2017, 5, 2784-2791.

38 P. Andrei, J. P. Zheng, M. Hendrickson and E. J. Plichta, J. Electrochem. Soc., 2010, 157, A1287.

39 S. Mamidi, A. D. Pathak, A. Gangadharan and C. S. Sharma, J. Power Sources, 2020, 473, 228600.

40 E. Martínez-Rosas, R. Vasquez-Medrano and A. FloresTlacuahuac, Comput. Chem. Eng., 2011, 35, 1937-1948.

41 H. Xia, L. Lu and G. Ceder, J. Power Sources, 2006, 159, 1422-1427.

42 N. Ding, J. Xu, Y. X. Yao, G. Wegner, X. Fang, C. H. Chen and I. Lieberwirth, Solid State Ionics, 2009, 180, 222-225. 